Research Article

\title{
A Comparative Study on Rock Properties in Splitting and Compressive Dynamic Tests
}

\author{
Nan Wu $\mathbb{D}^{1,2}$ Zhende Zhu, ${ }^{1,2}$ Yaojun Zhou, ${ }^{1,2}$ and Shihu Gao $\mathbb{D}^{1,2}$ \\ ${ }^{1}$ Key Laboratory of Ministry of Education for Geomechanics and Embankment Engineering, Hohai University, \\ Nanjing 210098, China \\ ${ }^{2}$ Jiangsu Research Center for Geotechnical Engineering Technology, Hohai University, Nanjing 210098, China
}

Correspondence should be addressed to Nan Wu; wunanhhu@hhu.edu.cn

Received 27 July 2018; Accepted 3 December 2018; Published 12 December 2018

Academic Editor: Yuri S. Karinski

Copyright (c) 2018 Nan Wu et al. This is an open access article distributed under the Creative Commons Attribution License, which permits unrestricted use, distribution, and reproduction in any medium, provided the original work is properly cited.

\begin{abstract}
The dynamic properties of rock in splitting (tensile) and compressive tests are the focus of rock dynamic mechanics research. In this study, a split Hopkinson pressure bar (SHPB) apparatus was used to assess the comparability and strain rate effect of rock samples under two kinds of load conditions. With an increase in impact velocity under compression and splitting (tensile) tests, the strain rate of the samples increased continuously. The rock properties and strain rate in the two kinds of samples exhibited clear similarities: the dimensionless stress-strain curves of the rock samples were similar under the same strain rates. The peak strength and elastic modulus of the two kinds of samples increased with an increase in the strain rate. The number of cracks increased from intergranular to transgranular failure. The rack initiation value of the two kinds of samples was close at the same strain rate and declined with an increase in the strain rate as evidenced by a power function.
\end{abstract}

\section{Introduction}

Many building structures are inseparable from the widely distributed rock mass in nature [1]. The deep tunnels, for example, are contained in complex rock masses, and this structure is possibly affected by dynamic loads such as impact blasting and seismic disturbance. These loads not only produce compressive load on the structure but also often produce tensile action [2]. Thus, the study on the tensile and compressive properties of rock materials under dynamic loading has important significance to the building structures [3-5].

Judging from the mechanical principle, rock damage can be divided into two basic forms: shear failure and tensile failure under dynamic loading. To a large extent, rock strength criteria are promoted by rock compressive shear failure strength theory, such as Mohr-Coulomb and Hoek-Brown theories. However, these classical strength theories are not applicable in many cases [6]. For example, with the increment of the depth of tunnel structure, hard rocks fail more often in slabbing or spalling rather than in shear under the action of high ground stress [7, 8]. Engineering rock mass is subjected to large compressive stress in one direction but remains free (or under slight compressive stress) in the orthogonal direction, leading to substantial lateral tensile deformation of rock mass due to Poisson's effect under the action of high ground stress. Because the tensile strength of rock mass is much less than the compressive strength, tensile damage during rock engineering can be easily produced. The classic Mohr-Coulomb criterion and empirical Hoek-Brown criterion are essential to shear failure of rock but are not suitable in this case.

In view of the above question, Stacey [9] proposed a simple extension strain criterion for brittle rock fracture, pointing out that extension fractures in brittle rock initiate when the total extension strain on the rock exceeds a critical value during the loading process. This method has achieved good results in work based on strain to measure rock damage; however, crack initiation is difficult to identify from axial stress compared to the volumetric strain curve. Martin and Chandler [10] proposed a solution using a plot of crack volumetric strain compared to axial strain. As strain gauge 
characteristics produce an inflection point during rock initiation, Song et al. [11] put forward a data analysis method that can be used to judge rock cracks with good application effects. The problem of crack initiation has thus been solved, leading to the development of a criterion that measures strain.

The extension strain criterion can be used not only to analyze the compressive failure of rock materials but also to calculate the tensile failure of rock materials, which provides conditions for comparative study of the similarity of rock materials under tensile and compressive loads. Also, according to elasticity theory, the maximum tensile strain critical value of rock is equivalent under tensile and compressive stresses [12], providing the theoretical premise for the similarity of rock at tensile and compressive properties. On this basis, Jin [13] carried out stress-feedback loading tests on three types of rock: sanchengmu-andesite, Laidaisandstone, and Tage tuff. Corresponding failure laws were obtained by analyzing test data of different rock samples under static tensile and compressive stresses. The static tensile and compressive force variation characteristics of the same rock were found to have strong similarities, but the test was unrelated to dynamic loading conditions.

This is because under the condition of dynamic loading, the rock material will have obvious strain rate effect $[14,15]$. Huang et al. [16] took Longyou sandstone as the research object and reported that dynamic tensile strength increased with the loading rate under dry and fully saturated conditions. In a dynamic compression test of rock, Feng et al. [17] discovered a relationship between the strength, deformation, energy characteristics, and failure mode of rock with the strain rate under coupled static and dynamic loads with different loadings. Many similar research studies have concluded that the "rate effect" during dynamic loading exerts a large influence on the physical and mechanical properties of rock materials [18-21]. Therefore, there are very few papers on the similarity of rock tensile and compressive properties under dynamic loading.

In this paper, the split Hopkinson pressure bar (SHPB) test equipment is used to analyze the physical and mechanical properties of rock under dynamic compression and splitting (tensile). The effects of the strain rate on stressstrain curves, elastic modulus, and failure patterns are analyzed under different impact velocities. The similarity of rock samples with different strain rates under splitting (tensile) and compressive actions is investigated, and the crack initiation value of samples is calculated by different methods, in order to reveal the influence of the strain rate on crack initiation in rock samples under different loading conditions.

\section{SHPB Test}

2.1. Sample Preparation. The samples consisted of granite obtained from a mining area in Xiamen, China, as shown in Figure 1(a). All the samples were $\Phi 80 \times 40 \mathrm{~mm}$ cylinders. Sample strain was tested using a strain gauge (model BFH120-3AA-D100) with a resistance value of $120 \mathrm{ohm}$ and sensitivity factor of $2.0 \pm 1 \%$. Vulcanized silicone rubber adhesive was coated on the strain gauge to reduce external vibrations. In the dynamic compressive splitting test, strain gauges (No. 1) were attached in the tensile direction of the sample, as shown in Figure 1(b), to record strain signals in that direction. Sample strain in the compression direction was measured using the strain gauge on the instrument. In the dynamic compression test, strain gauges (No. 2) were attached to the sample side, as illustrated in Figure 1(c), to record radial strain signals. The sample axial strain was measured using the strain gauge on the instrument.

2.2. Experimental Setup and Test Method. The dynamic tests were conducted in an SHPB apparatus with a diameter of $100 \mathrm{~mm}$, as shown in Figure 2. The apparatus consisted of a striking system with a length of $800 \mathrm{~mm}$, an input bar of $4100 \mathrm{~mm}$, an output bar of $3100 \mathrm{~mm}$, a momentum trap bar, a data acquisition system, and a high-speed camera system. The bar was made of $\mathrm{Cr}, \mathrm{Mn}$, and Si alloys; its Young's modulus $(E)$ was $209 \mathrm{GPa}$ with a yield strength greater than $400 \mathrm{MPa}$, density of $7890 \mathrm{~kg} / \mathrm{m}^{3}$, and wave propagation velocity $\left(C_{0}\right)$ of $5213 \mathrm{~m} / \mathrm{s}$. To ensure the waveform was nearly sinusoidal, a small piece of rubber with a diameter of $30 \mathrm{~mm}$ and thickness of $1.5 \mathrm{~mm}$ was used as the pulse shaper.

The initial positions of the striker bar and incident bar remained unchanged during the experiment. The compression and splitting (tensile) tests were conducted under different loading speeds by ejection from a striking bar at different speeds. The experimental data and failure process of each sample were recorded using a data acquisition system. The striking bar was fired at speeds of $3.5-3.7 \mathrm{~m} / \mathrm{s}$, $6.5-7.0 \mathrm{~m} / \mathrm{s}$, and $9.5-9.9 \mathrm{~m} / \mathrm{s}$ and generated different amplitude waveforms in the incident bar. The different strain rates of the samples were produced after inputting different stress amplitudes.

The compression and splitting (tensile) samples were tested at each impact speed, and multiple tests were performed under each operating condition to omit outliers and ensure good test repeatability; test data is presented in Table 1. A high-speed camera system was used to record the destruction process of the samples, as shown in Figure 3. Compression and tensile (splitting) tests at different impact velocities are carried out to study the effect of the strain rate on compression and tensile (splitting) properties of rock materials and to compare and analyze the similarities of rock materials in these two aspects.

\section{SHPB Test Results and Discussion}

3.1. Stress-Strain Curves. Rock strength and deformation are important parameters when measuring the loading ability of rock material, which is essential to understand rock properties and explore related failure mechanisms. The stressstrain curves of the samples under compression and splitting (tensile) and under different impact velocities were obtained through these tests, with the typical curves shown in Figure 4 . The impact velocity of the compressive samples was $3.52 \mathrm{~m} / \mathrm{s}$, and the peak strength was $87.11 \mathrm{MPa}$. When the impact velocity increased to $6.65 \mathrm{~m} / \mathrm{s}$ and $9.71 \mathrm{~m} / \mathrm{s}$, 


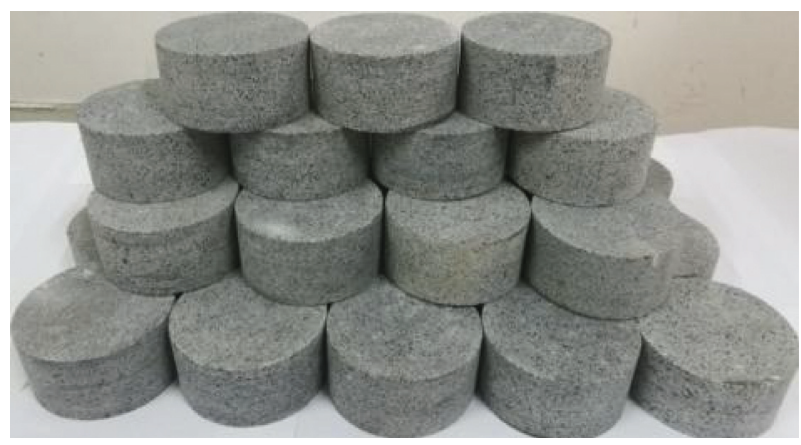

(a)

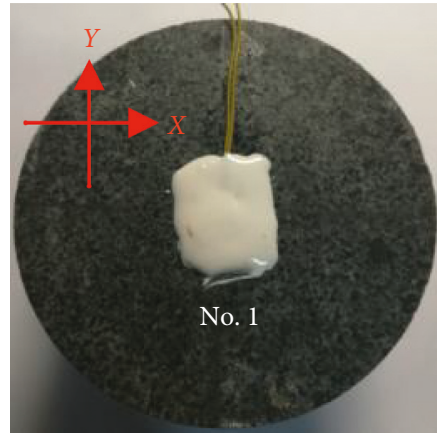

(b)

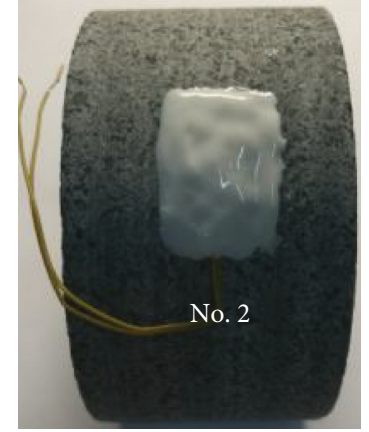

(c)

FIgURE 1: Samples for the SHPB test. (a) Samples. (b) Splitting (tensile) sample with attached strain gauge. (c) Compressive sample with attached strain gauge.

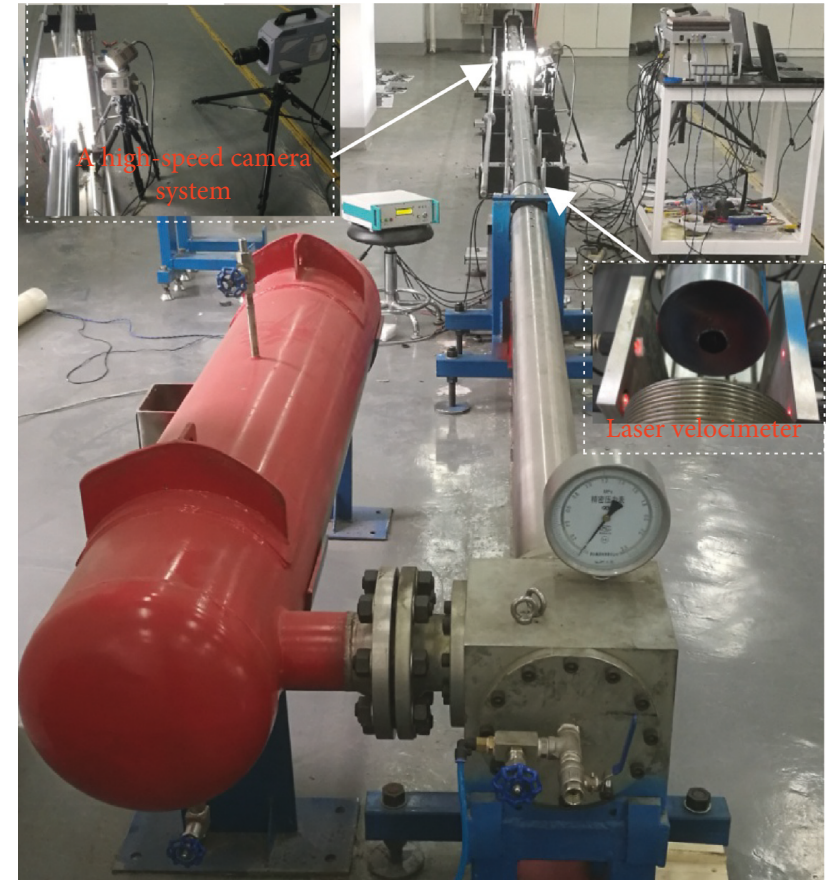

Figure 2: SHPB test equipment.

respectively, the peak strength rose to $216.92 \mathrm{MPa}$ and $262.33 \mathrm{MPa}$, an increase of $149.0 \%$ and $201.1 \%$ as shown in Figure 4(a). The impact velocity of the splitting samples was $3.61 \mathrm{~m} / \mathrm{s}$, and the peak strength was $17.51 \mathrm{MPa}$. When the impact velocity increased to $6.71 \mathrm{~m} / \mathrm{s}$ and $9.70 \mathrm{~m} / \mathrm{s}$, respectively, the peak strength rose to $26.36 \mathrm{MPa}$ and 34.31.33 $\mathrm{MPa}$, which is an increase of $50.63 \%$ and $95.95 \%$ as shown in Figure 4(b). When the impact velocity increased, so did the strain rate of the sample, and the peak strength rises rapidly. Other compression and splitting samples under the same test conditions exhibited the same laws as listed in Table 1.

Because of the different loading modes during the compression and splitting (tensile) tests, different impact loading velocities were used with samples to produce the same strain rate. When the compressive impact velocity was $6.6-7.0 \mathrm{~m} / \mathrm{s}$, the compressive strain rate of the sample was
$6.7-7.3 \mathrm{~s}^{-1}$, approximately equal to the tensile strain rate $\left(6.8-7.3 \mathrm{~s}^{-1}\right)$ of the samples at an impact velocity of $3.5-$ $3.7 \mathrm{~m} / \mathrm{s}$. However, the peak strength of compressive samples (205.98 MPa) was 11.26 times that of splitting (tensile) samples $(18.29 \mathrm{MPa})$. When the impact velocity increased, the strain rate was within the range of $12.1-13.6 \mathrm{~s}^{-1}$. The sample compression velocity was $9.7-9.9 \mathrm{~m} / \mathrm{s}$, and the tensile splitting velocity was $6.5-6.8 \mathrm{~m} / \mathrm{s}$. However, the peak strength of compressive samples $(265.39 \mathrm{MPa})$ was 10.29 times that of splitting (tensile) samples $(25.78 \mathrm{MPa})$. Rock has a tensile strength far less than the compressive strength. Specifically, the compressive strength of different rocks is 8-16 times greater than the tensile strength; similar conclusions have been obtained in many studies [22].

The typical dimensionless stress-strain curves were treated at a close strain rate loading of splitting (tensile) and compressive tests as depicted in Figure 4(c). Dimensionless treatment was carried out on the stress axis $(Y)$ and strain axis $(X)$ at the peak point of the stress-strain curve, respectively [21]. Figure 4(c) indicates that the compressive and splitting (tensile) samples underwent an approximate compaction stage and elastoplastic stage under the same strain rate, and the two curves demonstrated strong similarities before reaching peak strength. After that, the splitting (tensile) sample strength was immediately lost, and the compressive sample withstood a certain pressure before slowing down. As the strain rate increased, the elastoplastic stage of the two kinds of curves increased rapidly, and the two stages before peak strength were still close.

\subsection{Elastic Modulus. The elastic modulus of rock represents} a macroscopic synthesis embodiment of the internal microstructure to the external load response. According to the compression and splitting tests at different impact velocities, the corresponding initial elastic modulus $\left(E_{0}^{c}\right)$ and $50 \%$ peak strength elastic modulus $\left(E_{50}^{c}\right)$ appear in Table 1, which hold great significance for the elastoplastic phase, failure mode, and mechanism of the rock material. The test results are shown in Figure 5. As the impact velocities increased, the initial elasticity modulus $\left(E_{0}^{c}\right)$ increased from $6.82 \mathrm{GPa}$ to $40.73 \mathrm{GPa}$ and $256.69 \mathrm{GPa}$, respectively. The corresponding $50 \%$ peak strength elastic modulus $\left(E_{50}^{c}\right)$ increased from 
TABLE 1: Experimental data in the SHPB test.

\begin{tabular}{|c|c|c|c|c|c|c|c|}
\hline \multirow{2}{*}{ Sample number } & \multirow{2}{*}{ Impact velocity $(\mathrm{m} / \mathrm{s})$} & \multirow{2}{*}{ Strain rate $\left(\mathrm{S}^{-1}\right)$} & \multicolumn{2}{|c|}{$E(\mathrm{GPa})$} & \multirow{2}{*}{ Peak strength $(\mathrm{MPa})$} & \multicolumn{2}{|c|}{ Crack initiation value } \\
\hline & & & $E_{0}$ & $E_{50}$ & & Method 1 & Method 2 \\
\hline C-A-1 & 3.52 & 4.91 & 6.20 & 10.64 & 87.11 & $1.64 E-4$ & $1.61 E-4$ \\
\hline C-A-2 & 3.42 & 3.70 & 7.01 & 12.11 & 80.31 & $1.59 E-4$ & $1.63 E-4$ \\
\hline C-A-3 & 3.46 & 4.10 & 7.26 & 11.92 & 83.17 & $1.72 E-4$ & $1.69 E-4$ \\
\hline C-B-1 & 6.65 & 7.04 & 42.82 & 61.58 & 216.92 & $1.17 E-4$ & $1.21 E-4$ \\
\hline C-B-2 & 6.91 & 7.36 & 40.99 & 67.23 & 205.91 & $1.37 E-4$ & $1.31 E-4$ \\
\hline C-B-3 & 6.67 & 6.74 & 38.37 & 67.71 & 195.11 & $1.36 E-4$ & $1.39 E-4$ \\
\hline $\mathrm{C}-\mathrm{C}-1$ & 9.71 & 12.90 & 258.11 & 334.08 & 262.33 & $9.66 E-5$ & $9.27 E-5$ \\
\hline $\mathrm{C}-\mathrm{C}-2$ & 9.77 & 12.13 & 270.19 & 320.11 & 255.52 & $1.14 E-4$ & $1.04 E-4$ \\
\hline $\mathrm{C}-\mathrm{C}-3$ & 9.90 & 13.59 & 241.77 & 319.71 & 278.33 & $1.04 E-4$ & $8.95 E-5$ \\
\hline T-A-1 & 3.61 & 6.89 & 32.08 & 53.76 & 17.51 & $1.31 E-4$ & $1.37 E-4$ \\
\hline T-A-2 & 3.67 & 7.26 & 35.94 & 52.70 & 18.38 & $1.23 E-4$ & $1.19 E-4$ \\
\hline T-A-3 & 3.55 & 7.10 & 32.62 & 51.09 & 18.99 & $1.28 E-4$ & $1.15 E-4$ \\
\hline T-B-1 & 6.71 & 12.01 & 103.38 & 141.67 & 26.36 & $1.08 E-4$ & $1.01 E-4$ \\
\hline T-B-2 & 6.58 & 13.10 & 101.12 & 135.74 & 25.05 & $1.15 E-4$ & $1.13 E-4$ \\
\hline T-B-3 & 6.70 & 12.50 & 93.52 & 144.38 & 25.92 & $1.21 E-4$ & $1.27 E-4$ \\
\hline T-C-1 & 9.70 & 19.10 & 334.90 & 438.59 & 34.31 & $9.28 E-5$ & $9.22 E-5$ \\
\hline T-C-2 & 9.51 & 16.62 & 317.77 & 441.51 & 36.87 & $9.50 E-5$ & $9.30 E-5$ \\
\hline T-C-3 & 9.57 & 17.30 & 320.91 & 450.10 & 36.19 & $9.28 E-5$ & $8.36 E-5$ \\
\hline
\end{tabular}

11.56 GPa to $65.51 \mathrm{MPa}$ and $324.63 \mathrm{GPa}$, respectively (Figure 5(a)). Additionally, as the impact velocity increased, the initial elasticity modulus $\left(E_{0}^{c}\right)$ of the splitting test sample increased from $33.55 \mathrm{GPa}$ to $99.34 \mathrm{GPa}$ and $324.53 \mathrm{GPa}$, respectively; the corresponding $50 \%$ peak strength elasticity modulus $\left(E_{50}^{c}\right)$ increased from $52.52 \mathrm{GPa}$ to $140.6 \mathrm{GPa}$ and 443.40 GPa, respectively, as illustrated in Figure 5(b).

The stress-strain curves of rock before reaching peak strength revealed a compaction stage and elastoplastic stage under dynamic loading. The initial elasticity modulus $\left(E_{0}\right)$ and $50 \%$ peak strength elasticity modulus $\left(E_{50}\right)$ are important parameters reflecting the compression phase and elastic-plastic phase, and their ratio $\left(E_{0} / E_{50}\right)$ depicts the difference between the two phases. As the impact velocity increased, the ratio of compression samples rose from 59\% to $62.17 \%$ and $79.07 \%$, respectively, indicating a substantial increase. Furthermore, the compressive splitting (tensile) samples showed the same regularity, increasing from $63.88 \%$ to $70.65 \%$ and $73.19 \%$ as depicted in Figure 5(c).

During compression tests and splitting (tensile) tests, the initial elastic modulus $\left(E_{0}\right)$ and $50 \%$ peak strength elastic modulus $\left(E_{50}\right)$ exhibited the same variation rule as the loading rate increased. The elastic modulus was sensitive to the strain rate of rock samples, indicating a similarity between the compressive and splitting (tensile) loading responses. Moreover, the ratio of the two elastic moduli showed the same trend as the loading rate. The initial elastic modulus $\left(E_{0}\right)$ and $50 \%$ peak strength elastic modulus $\left(E_{50}\right)$ reflected the compaction stage and elastoplastic stage properties; variations in this ratio revealed that the trend of the curves in each stage was similar.

3.3. Failure Mode. A FASTCAM SA-Z (200K-C-32 GB) high-speed camera system (Japan) was used to record the failure pattern of the samples during the loading process; photos are shown in Figure 3. Without obstructions on the sides of the samples in the SHPB apparatus, the failure mode of the half-circumference surface was randomly analyzed by the high-speed camera. To depict the development of rock cracks at different impact velocities, the high-speed camera system was used to photograph the sample failure process. Resultant images were processed by binary image processing technology [23] as shown in Figures 3(a) and 3(c).

Figure 3(a) presents a series of photos from the compression test process at different impact velocities. The samples contained no initial fissures before loading, indicating good integrity. After the sample impact was completed, the radial tensile crack initiation point randomly appeared once the radial strength was reached, although the crack area was small at a low-velocity impact. When the impact velocity increased, the number and areas of cracks increased when the radial strength was reached (i.e., the radial tensile crack initiation point), showing many simultaneous occurrences in the observed region. When the sample reached peak strength, the area and the number of cracks in the observed area increase greatly. The binary image photo indicates that the cracks appeared in the parallel loading direction, which was also the direction of principal stress $\left(\sigma_{1}\right)$. The length-diameter ratio of the rock sample was 0.5 ; the sample was not long enough to cause shear damage. Under this condition, rocks tend to fail more often during slabbing or spalling (two kinds of extension failure) rather than shearing. Spalls or slabs occurred parallel to the direction of the maximum compressive load. The same result has been obtained in several papers and has been validated by scanning electron microscope images at a mesoscale $[24,25]$.

The crushing state of the samples after impact compression loading is shown in Figure 3(b). As the impact velocity increased, the samples were fed more energy, resulting in a continuous increase in the degree of fragmentation. The size of the samples was smaller, the quantity increased, and the powder-like debris increased at the same 

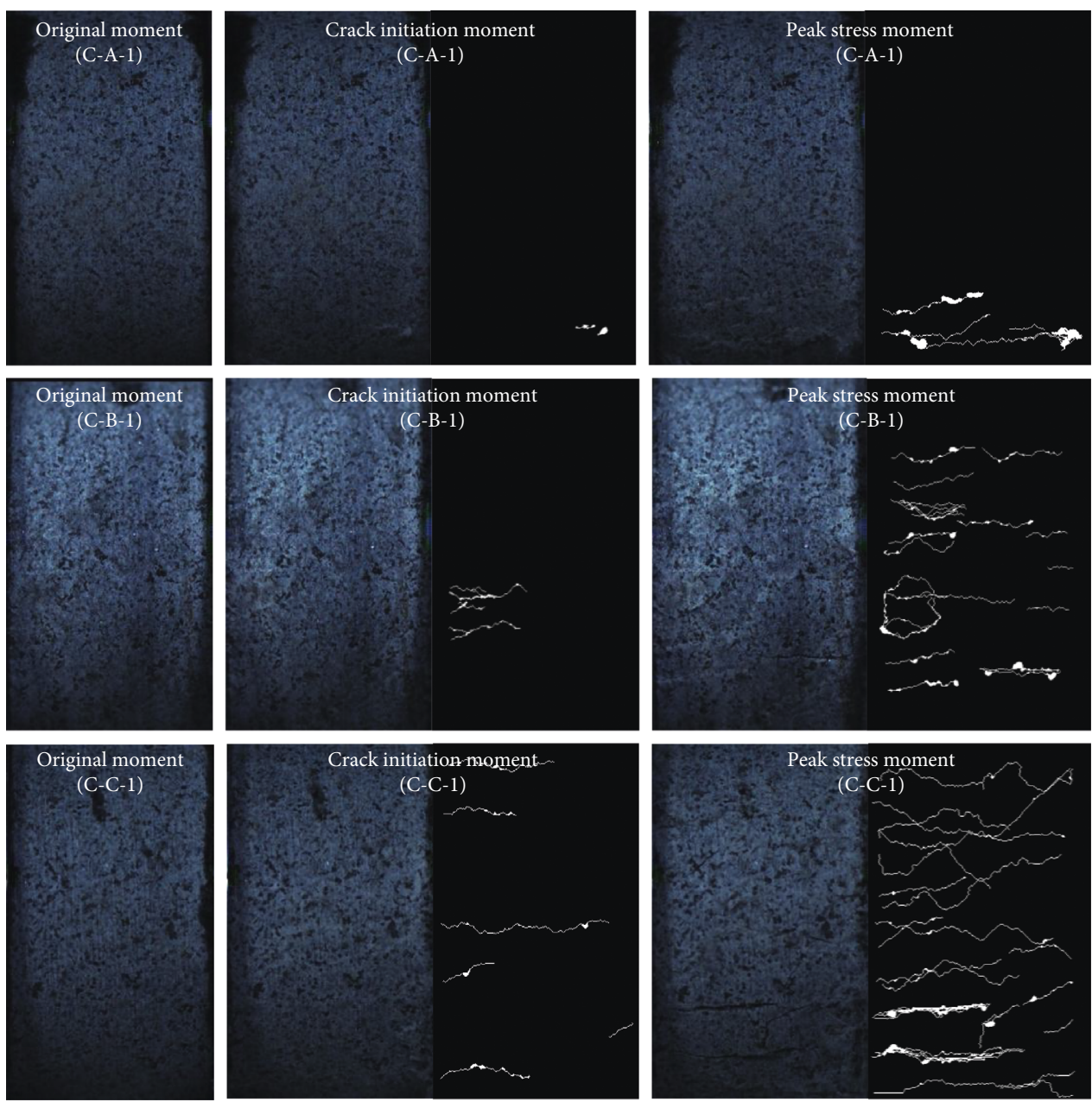

(a)
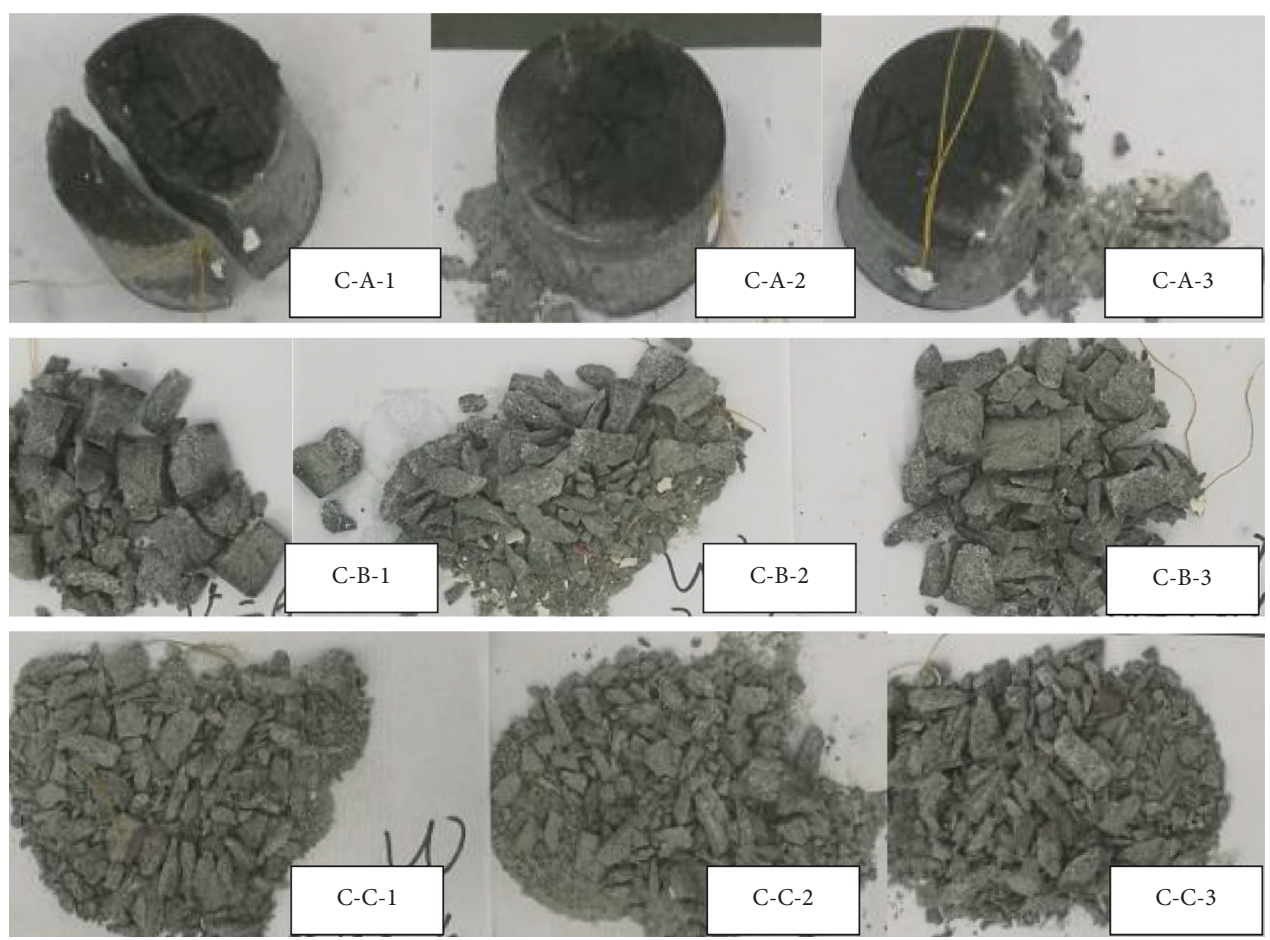

(b)

Figure 3: Continued. 

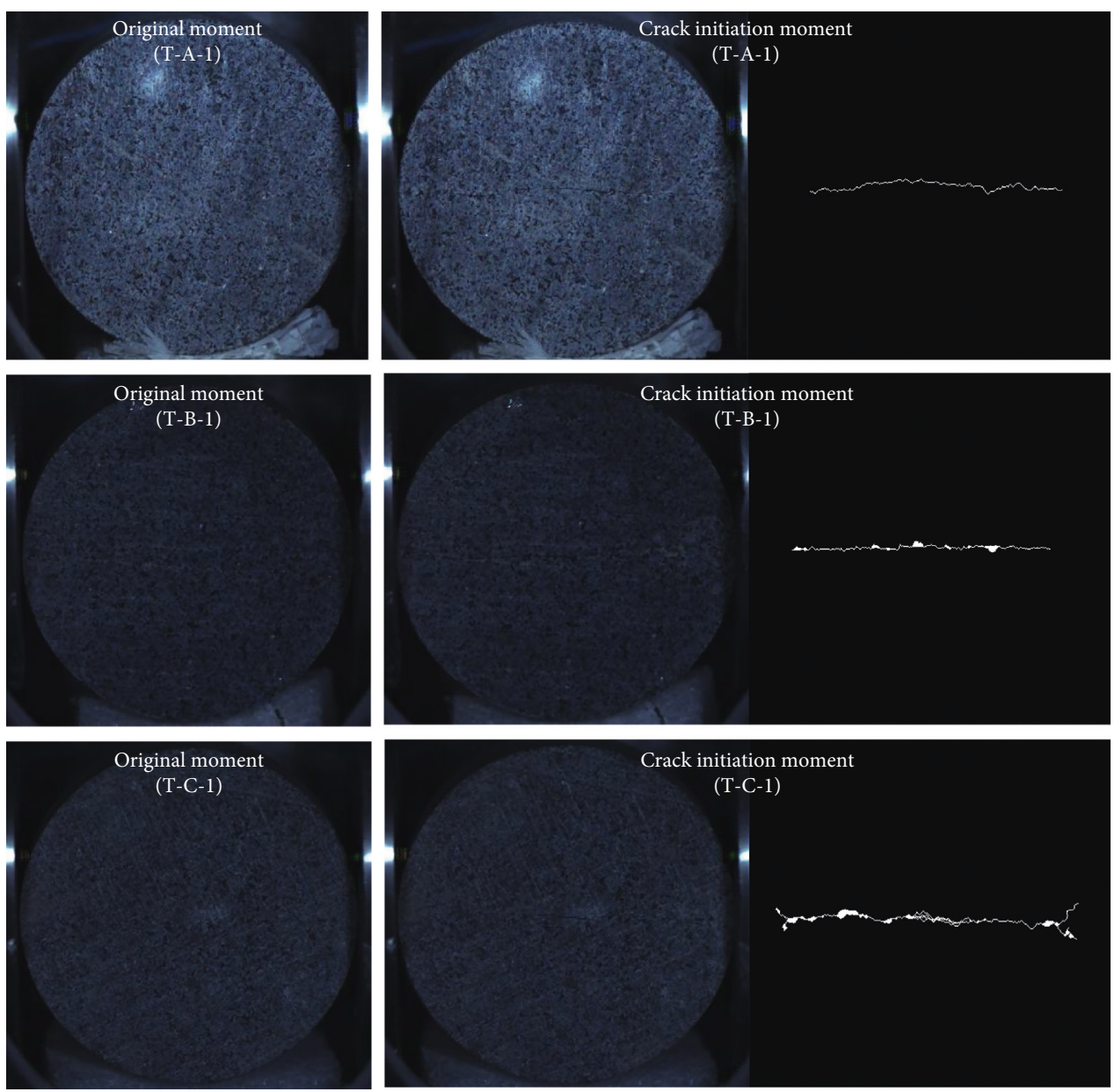

(c)

Figure 3: Photos of sample destruction morphology at different impact velocities. (a) During compression process. (b) After compression. (c) During the splitting (tensile) process.

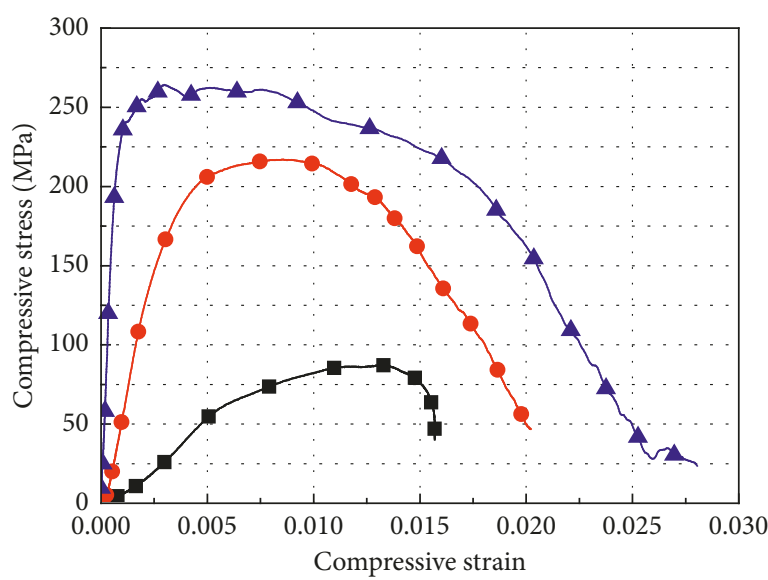

Unit: $\mathrm{m} / \mathrm{s}$

$\rightarrow \mathrm{C}-\mathrm{A}-1(V=3.52)$

-C C-B-1 $(V=6.65)$

$\neg \mathrm{C}-\mathrm{C}-1(V=9.71)$

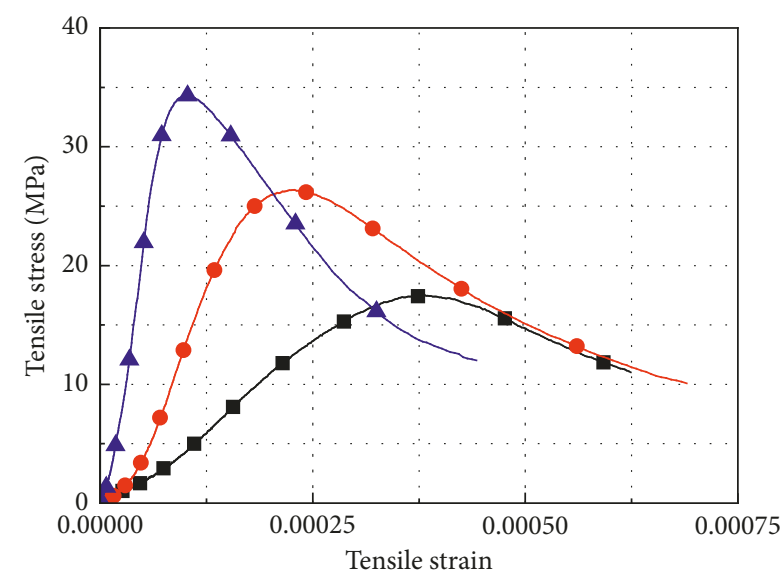

Unit: $\mathrm{m} / \mathrm{s}$

- $\mathrm{T}-\mathrm{A}-1(V=3.61)$

$\longrightarrow \mathrm{T}-\mathrm{B}-1(V=6.71)$

$\neg \mathrm{T}-\mathrm{C}-1(V=9.70)$

(a)

Figure 4: Continued. 

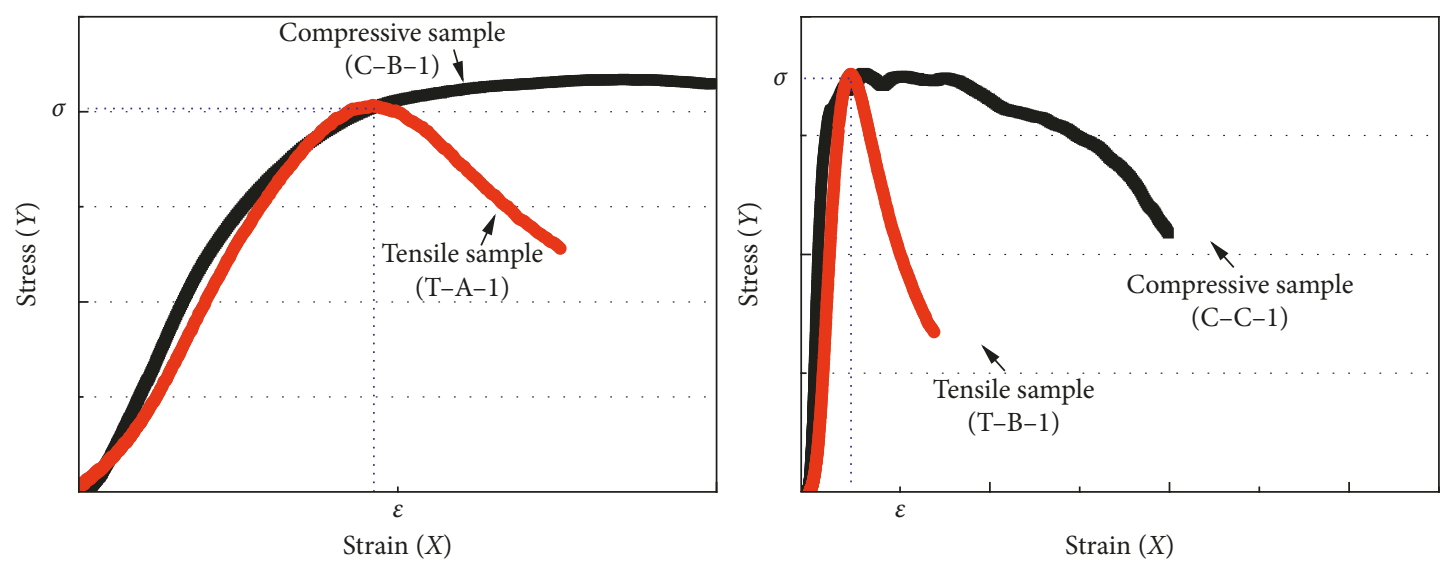

(c)

FIgURE 4: Typical stress-strain curve of samples at different impact velocities. (a) Compression test curves. (b) Splitting (tensile) test curves. (c) Dimensionless curve.

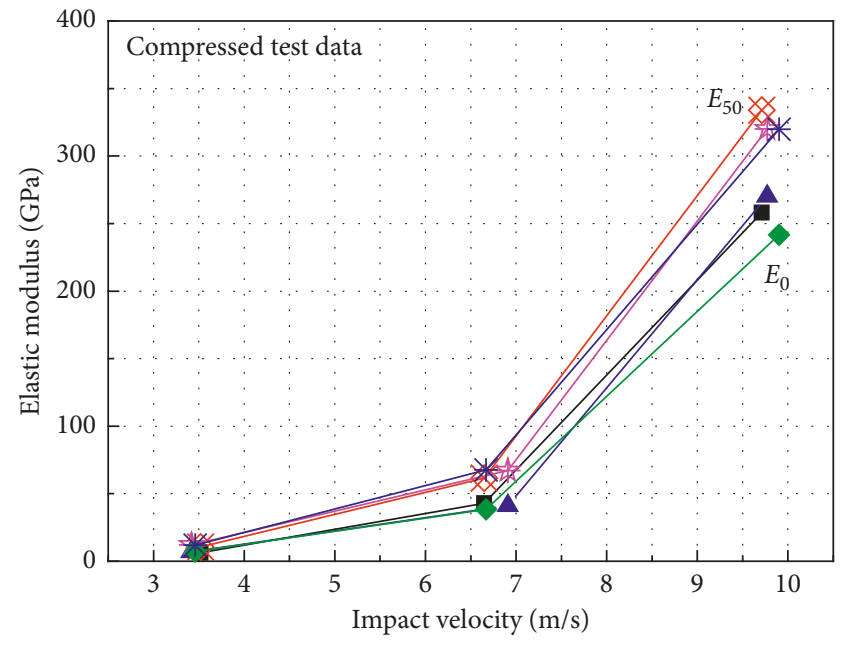

(a)

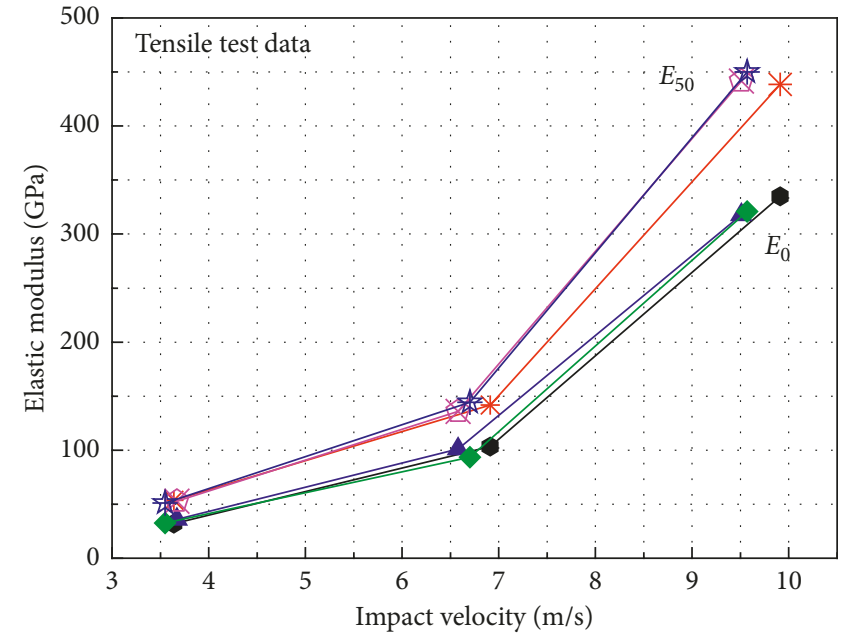

(b)
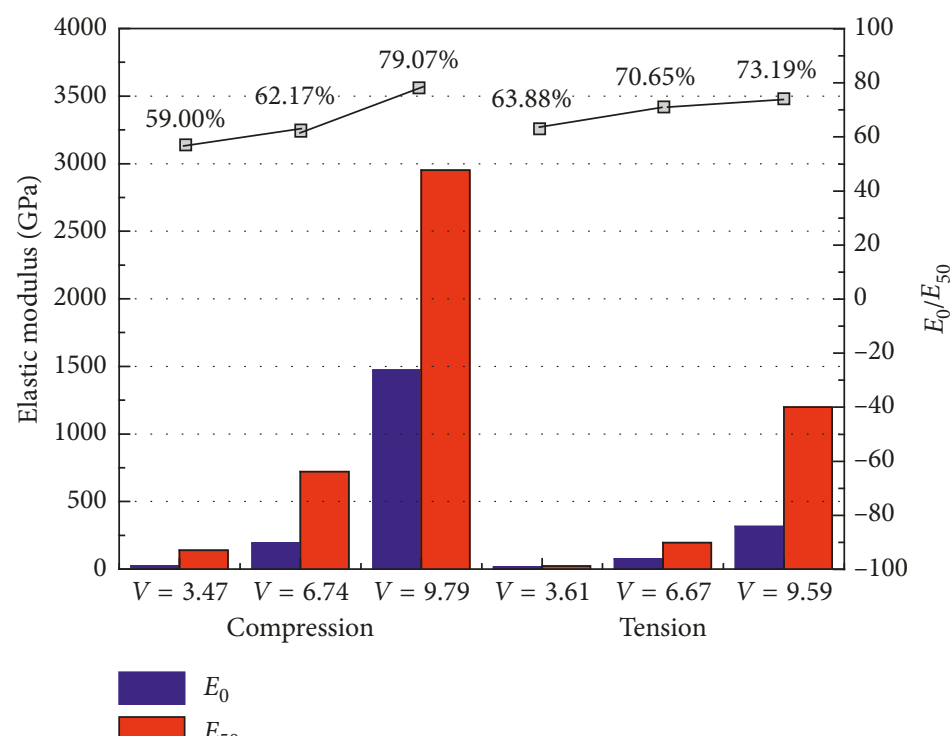

(c)

FIgURE 5: Elasticity modulus of samples at different impact velocities. (a) Compression test. (b) Splitting (tensile) test. (c) Bar graph. 
time. When the tensile strength of the samples was reached in the compressive splitting test, a crack first generated in the center of the disk and then extended to both sides as shown in Figure 3(c). From the binary image photo, once a crack occurred, the crack length was nearly the same at the moment of crack initiation and remained nearly unchanged as the strain rate increased, presumably because the tensile strength of rock is far less than the compressive strength; once the split sample macroscopic crack appeared (after reaching the crack strength), it expanded rapidly and achieved the tensile strength (peak strength) before being destroyed instantly. As the strain rate increased, the linear degree of the crack increased and became increasingly straight. This phenomenon was mainly due to the input of more energy in rock unit time such that the crack along the weakest path at a low strain rate evolved along the maximum energy dissipation path at a high strain rate. The cracks in the rocks continued to change from intergranular to transgranular, which consumed more energy and exhibited higher peak strength upon macroscopic examination [26].

\section{Extension Strain of Compression and Splitting Tests}

4.1. Value of Crack Initiation. The strength theory of rock is the key in research on rock mechanics and holds great significance for rock properties and failure mechanisms. Given the limitations of the traditional rock strength theory in explaining the phenomenon of rock slabbing (or spalling) failure, strain theory has been widely used as a strength theory. In strain theory, the value of crack initiation in rock is paramount.

To solve the value of rock crack initiation, Stacey [17] suggested that a turning point in the curve's slope of axial versus radial strain could be interpreted as axial macroscale fracturing; a form of critical extensional strain could thus be determined from test results. The points identified by this method $(\operatorname{method} 1)$ in the slope change of the curves were obtained and appear as points 1, 2, and 3 in Figure 6(a) and $1^{\prime}, 2^{\prime}$, and $3^{\prime}$ in Figure 6(b).

In this test, the radial tensile strain produced by the compression sample and the tensile strain perpendicular to the loading direction produced by the split sample were measured using the strain gauge attached to the sample surface as shown in Figures 1(b) and 1(c). As strain gauge characteristics produce an inflection point during rock initiation, Song et al. [11] put forward a data analysis method (method 2) that can be used to judge rock cracks with good application effects.

The application of Song's method (method 2) is easier to get the value of crack initiation. In compression tests, when the samples were subjected to compression impact, the radial strain reached the critical value of tensile strain, and cracks began to form; however, the likelihood of cracks in the area covered by the strain gauge was quite small. Because the appearance of cracks led to changes in the macroscopic physical and mechanical properties of the samples, the data from the strain gauge changed suddenly. The slope of the time versus radial strain curve demonstrated a clear turning point as shown in Figure 6(c) A, B, and C. In the splitting test, when the sample reached tensile strength along the tensile direction ( $Y$ direction), it began to crack. Therefore, when the crack extended to the area covered by the strain gauge, $\sigma_{y}=0$ in the vicinity of the free surface of the crack, hence the decrease in tensile strain in the initiation zone as shown in Figure 6(d) $A^{\prime}, B^{\prime}$ and $C^{\prime}$. The strain gauge was not broken at this moment, and however, the data collected by the strain gauge showed a trend of first declining and then rising. The crack then continued to expand along the loading direction, and the strain gauge was pulled out; at that point, the data gathered by the strain gauge increased to infinity until they were limited by the range of the high-dynamic strain indicator.

The crack initiation values derived using the two methods were quite close, verifying the accuracy of the results and the reliability of the method. Figure 6(e) and Table 1 reveal that, with an increase in impact speed, the values of crack initiation in the compression sample and splitting (tensile) sample gradually decreased. As the strain rate grew, more energy was input into the rock sample per unit time, and an increase in the speed of energy input forced the crack to dissipate energy more quickly. The brittleness enhancement of rock material with macroscopic crack behavior changed from intergranular to transgranular at a mesoscopic scale, and the crack became straighter at the macrolevel. The value of crack initiation decreased with an increase in the strain rate, and the number of cracks increased as soon as cracking begin to appear.

\subsection{Uniformity of Strain Rate Effect in Splitting and Com-} pressive Tests. In the dynamic impact test, the following patterns appeared in the axial versus radial strain curves of the compression and splitting (tensile) samples, as shown in Figure 7(a). The strain rates were close to those of the C-B series compression samples and T-A series splitting (tensile) samples, each ranging from 6.7 to $7.4 \mathrm{~s}^{-1}$. The crack initiation value was also highly similar in both kinds of samples, between $1.17 E-4$ and $1.37 E-4$ which is shown as "a" in Figure 7(a), at which point the sample reached the maximum extension strain of cracking. The same law appeared in the compression $\mathrm{C}-\mathrm{C}$ series samples and $\mathrm{T}-\mathrm{B}$ series splitting (tensile) samples; the strain rate was between 12.1 and $13.6 \mathrm{~s}^{-1}$, and the crack initiation value ranged from $0.9 \mathrm{E}-4$ to $1.3 E-4$ which is shown as "b" in Figure $7(a)$. The regularity of the strain rate and crack initiation value under dynamic loading conditions revealed a power function that could be used to describe the curve law as indicated in the following equation:

$$
1 \times 10^{5} y=33.15(x+0.87)^{-0.659}+4.75 .
$$

where $X$ is the strain rate and $Y$ is radial strain as shown in Figure $7(\mathrm{~b})$. The fitting curve adj. $R^{2}$ was 0.86 , and the reduced chi-square was 0.81 , implying that the fitting results accurately reflected the law of the data.

The crack initiation value produced by the compression or splitting (tensile) test samples was close to the strain rate and exhibited the same change trend. The Brazil disc dynamic 

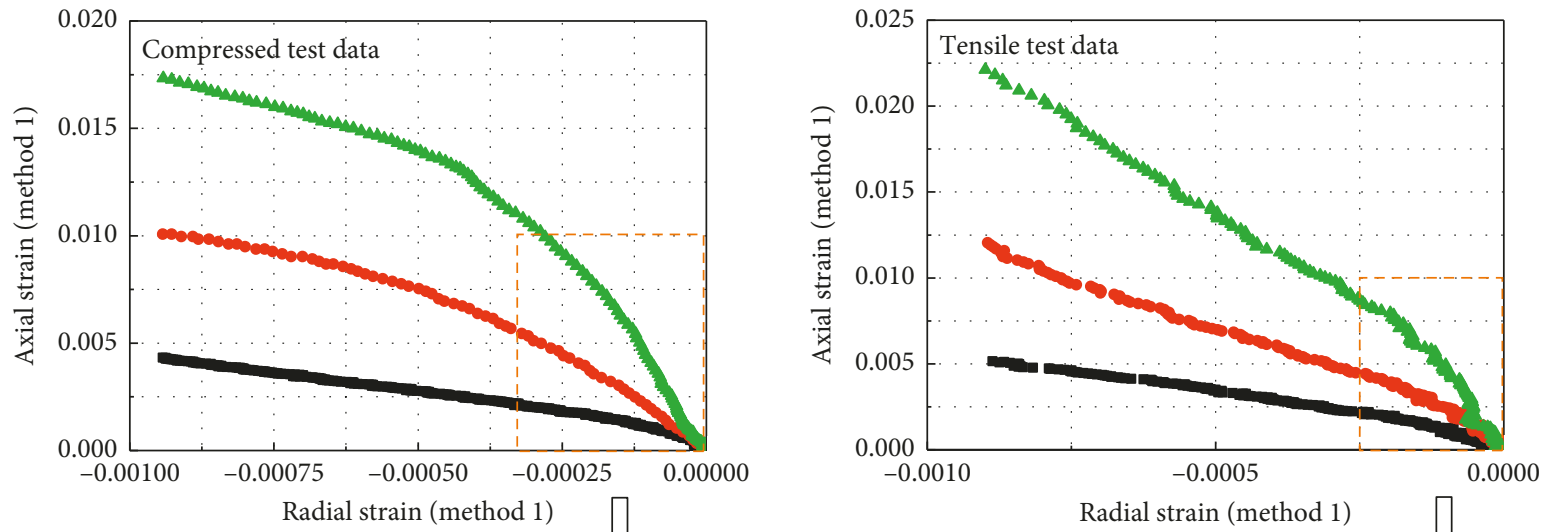

Unit: $\mathrm{m} / \mathrm{s}$

- C-C-1 $(V=9.71)$

- C-B-1 $(V=6.65)$

Unit: $\mathrm{m} / \mathrm{s}$

- T-C-1 $(V=9.70)$

- T-B-1 $(V=6.71)$

A C-A-1 $(V=3.52)$

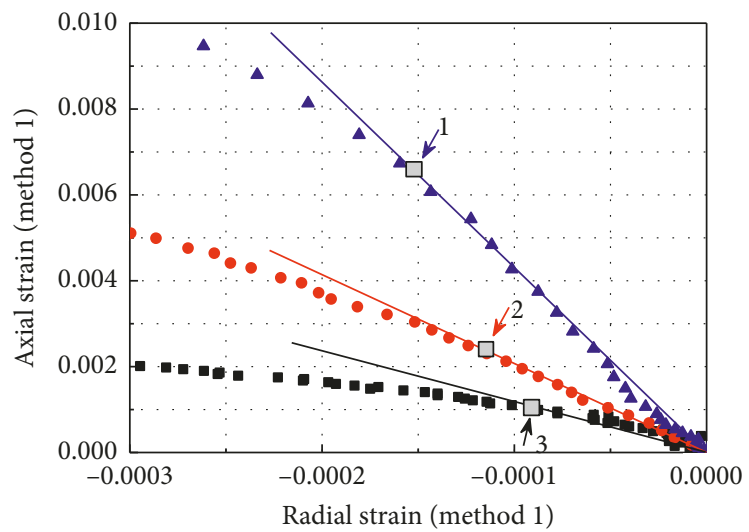

$\Delta$ T-A-1 $(V=3.61)$

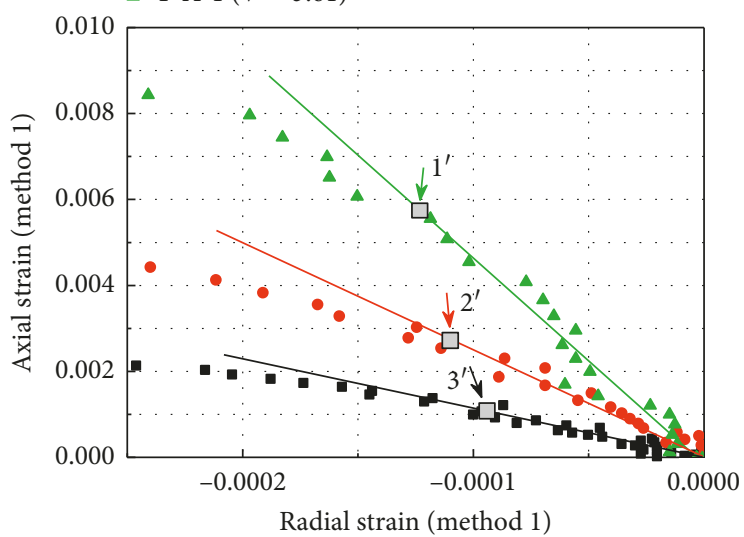

Unit: $\mathrm{m} / \mathrm{s}$

Unit: $\mathrm{m} / \mathrm{s}$

- C-C-1 $(V=9.71)$

- $\mathrm{C}-\mathrm{B}-1(V=6.65)$

( C-A-1 $(V=3.52)$

- T-C-1 $(V=9.70)$

- T-B-1 $(V=6.71)$

- T-A-1 $(V=3.61)$

(a)

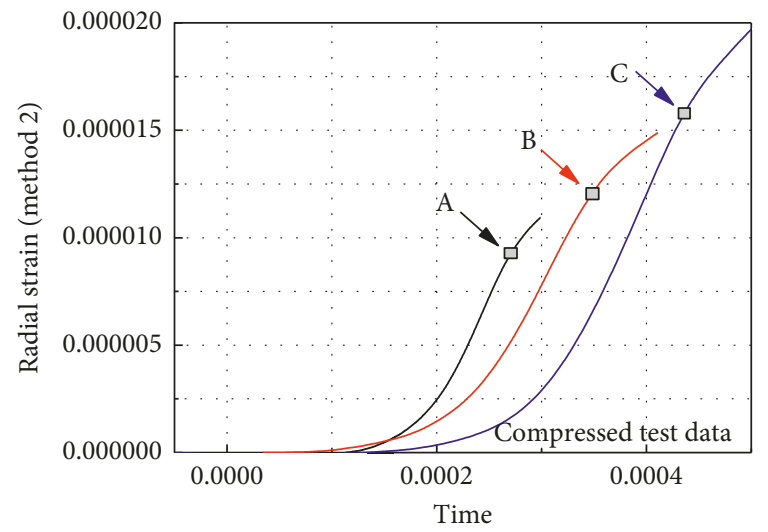

Unit: $\mathrm{m} / \mathrm{s}$

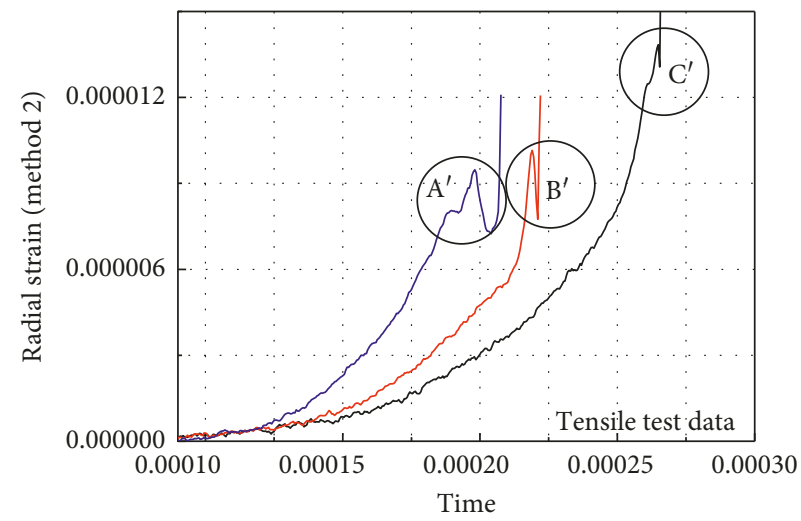

C-C-1 $(V=9.71)$

Unit: $\mathrm{m} / \mathrm{s}$

C-B-1 $(V=6.65)$

C-A-1 $(V=3.52)$

(c)

T-C-1 $(V=9.70)$

- T-B-1 $(V=6.71)$

— T-A-1 $(V=3.61)$

FIgURE 6: Continued. 


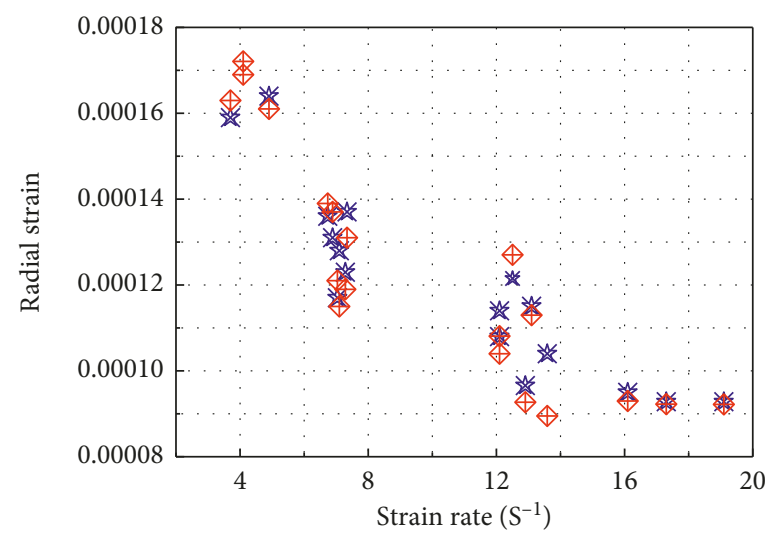

$\oplus$ Stacey's method (method 1$)$

谈 Song's method (method 2$)$

(e)

FiguRE 6: Extension strain of samples at different impact velocities. (a, b) Stacey's method (method 1). (c, d) Song's method (method 2). (e) Comparison of method 1 and method 2.

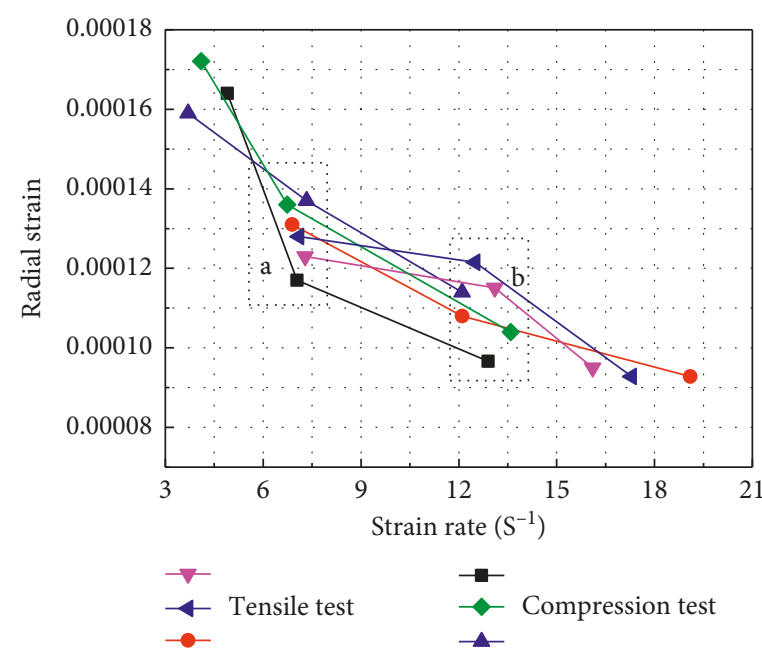

(a)

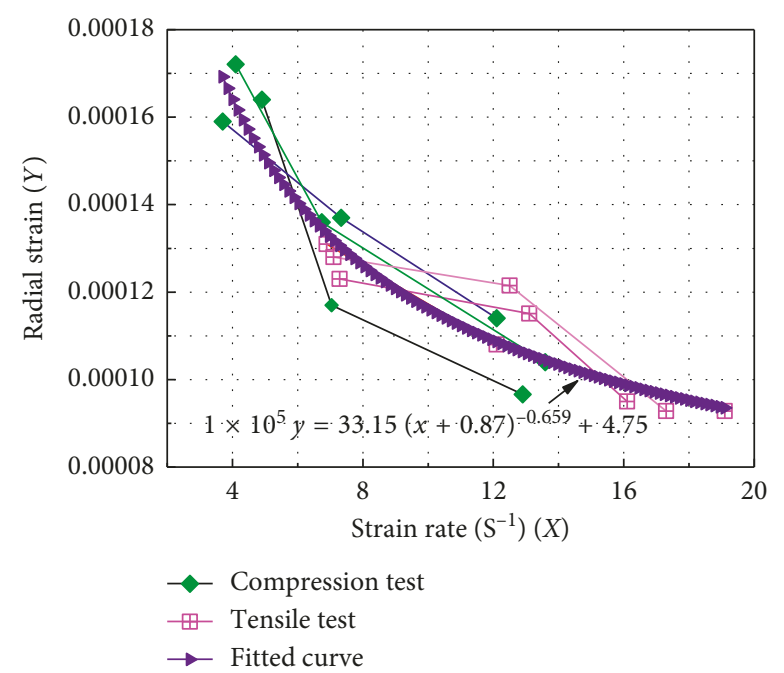

(b)

Figure 7: Crack initiation value of compression and splitting (tensile) samples. (a) Curve of radial strain and strain rate. (b) Fitting curve of test data.

splitting-loading test is essentially an indirect tensile loading test; tensile cracking reflected Poisson's effect on rock material in the direction perpendicular to the loading direction, and the radial tensile strain of the compression sample was also due to Poisson's effect of rock material. Poisson's ratio depicts the material properties of rock, and Poisson's ratio of the same rock was found to be equal under identical loading conditions; accordingly, the compression and splitting (tensile) test samples showed strong approximation under the same dynamic loading conditions.

\section{Conclusions}

By comparing the similarities of compressive and splitting (tensile) properties of rock materials in stress-strain, elastic modulus, and failure modes, the changing laws of rock materials under dynamic loads are more comprehensively recognized. The radial strain versus strain rate curves under compressive and splitting (tensile) loads based on the value of crack initiation are unified, and the curve law (regular expressions) are helpful to improve the accuracy of stability judgment of deep tunnels and underground caverns under complex high ground stress, and the following conclusions can be drawn:

(1) In dynamic loading, the strength of rock increased with the strain rate under compression and splitting (tensile). The compression strength of Xiamen granite was 10-12 times higher than compressive splitting (tensile) at the same strain rate. Before reaching peak strength, the stress-strain curves were 
highly similar in rock compression and splitting (tensile) tests.

(2) The initial elastic modulus of the rock sample increased along with the strain rate under dynamic loading conditions, and the elastic modulus at 50\% peak strength showed the same rule in compression and splitting (tensile) tests.

(3) The compressive sample at a length-diameter ratio of 0.5 exhibited slabbing or spalling failure under dynamic loading. As the strain rate increased, the area and quantity of cracks increased rapidly. The splitting (tensile) sample cracked from the center of the disc, and the sample lost its tensile strength once the crack was produced immediately.

(4) The crack initiation value of the two kinds of samples decreased as the strain rate increased. The rock initiation values of the two samples were quite close at the same strain rate before decreasing gradually with an increase in the strain rate. This process conformed to the power function law.

\section{Data Availability}

And, the experimental data used to support the findings of this study are available from the corresponding author upon request.

\section{Conflicts of Interest}

The authors declare that they have no conflicts of interest.

\section{Acknowledgments}

The authors are grateful to the National Program on Key Basic Research Project (973 Program) (2015CB057903), the National Natural Science Foundation of China (51379065), and the Fundamental Research Funds for the Central Universities (2015B35214) for the financial support.

\section{References}

[1] S. Liu and J. $\mathrm{Xu}$, "Effect of strain rate on the dynamic compressive mechanical behaviors of rock material subjected to high temperatures," Mechanics of Materials, vol. 82, pp. 28-38, 2015.

[2] T. Nonaka, R. J. Clifton, and T. Okazaki, "Longitudinal elastic waves in columns due to earthquake motion," International Journal of Impact Engineering, vol. 18, no. 7-8, pp. 889-898, 1996.

[3] X.-P. Lai, M.-F. Cai, F.-H. Ren, P.-F. Shan, F. Cui, and J.-T. Cao, "Study on dynamic disaster in steeply deep rock mass condition in urumchi coalfield," Shock and Vibration, vol. 2015, Article ID 465017, 8 pages, 2015.

[4] Y. S. Miao, X. J. Li, H. H. Yan, X. H. Wang, and J. P. Sun, "Experimental study of bilinear initiating system based on hard rock pile blasting," Shock and Vibration, vol. 2017, Article ID 3638150, 9 pages, 2017.

[5] T. Saksala, D. Gomon, M. Hokka, and V.-T. Kuokkala, "Numerical and experimental study of percussive drilling with a triple-button bit on Kuru granite," International Journal of Impact Engineering, vol. 72, pp. 56-66, 2014.
[6] M. Alber and J. Heiland, "Investigation of a limestone pillar failure Part 1: geology, laboratory testing and numerical modeling," Rock Mechanics and Rock Engineering, vol. 34, no. 3, pp. 167-186, 2001.

[7] J. Wesseloo and T. R. Stacey, "A reconsideration of the extension strain criterion for fracture and failure of rock," Rock Mechanics and Rock Engineering, vol. 49, no. 12, pp. 46674679, 2016.

[8] M. Nicksiar and C. D. Martin, "Evaluation of methods for determining crack initiation in compression tests on lowporosity rocks," Rock Mechanics and Rock Engineering, vol. 45, no. 4, pp. 607-617, 2012.

[9] T. R. Stacey, "A simple extension strain criterion for fracture of brittle rock," International Journal of Rock Mechanics and Mining Sciences \& Geomechanics Abstracts, vol. 18, no. 6, pp. 469-474, 1981.

[10] C. D. Martin and N. A. Chandler, "The progressive fracture of Lac du Bonnet granite," International Journal of Rock Mechanics and Mining Sciences \& Geomechanics Abstracts, vol. 31, no. 6, pp. 643-659, 1994.

[11] X. L. Song, Q. Z. Wang, and H. P. Xie, “A simple method for determining crack initiation and propagation in the dynamic splitting test," Journal of Sichuan University (Engineering Science Edition), vol. 39, no. 1, pp. 63-68, 2007.

[12] J. H. Ye, J. S. Yu, X. Liu, and Y. Wang, "Experimental research on the difference between maximum tensile strains of different rock specimens under uniaxial compressing and splitting lads," Earth and Environment, vol. 33, no. Sl, pp. 562-567, 2005.

[13] F. N. Jin, "Comparison of tensile and compressive behaviours of rock," Chinese Journal of Geotechnical Engineering, vol. 20, no. 2, pp. 31-33, 1998.

[14] K. Xia and W. Yao, "Dynamic rock tests using split Hopkinson (Kolsky) bar system-a review," Journal of Rock Mechanics and Geotechnical Engineering, vol. 7, no. 1, pp. 27-59, 2015.

[15] A. Fakhimi, P. Azhdari, and J. Kimberley, "Physical and numerical evaluation of rock strength in Split Hopkinson Pressure Bar testing," Computers and Geotechnics, vol. 102, pp. 1-11, 2018.

[16] S. Huang, R. Chen, and K. W. Xia, "Quantification of dynamic tensile parameters of rocks using a modified Kolsky tension bar apparatus," Journal of Rock Mechanics and Geotechnical Engineering, vol. 2, no. 2, pp. 162-168, 2010.

[17] P. Feng, F. Dai, Y. Liu, N. Xu, and P. Fan, "Effects of coupled static and dynamic strain rates on mechanical behaviors of rock-like specimens containing pre-existing fissures under uniaxial compression," Canadian Geotechnical Journal, vol. 55, no. 5, pp. 640-652, 2018.

[18] S. Mishra, T. Chakraborty, V. Matsagar, J. Loukus, and B. Bekkala, "High strain rate charactterization of deccan trap rocks using SHPB device," Journal of Materials in Civil Engineering, vol. 30, no. 5, article 04018059, 2017.

[19] H. Li, H. Li, B. Gao, D. Jiang, and J. Feng, "Study of acoustic emission and mechanical characteristics of coal samples under different loading rates," Shock and Vibration, vol. 2015, Article ID 458519, 11 pages, 2015.

[20] F. Q. Gong, H. Ye, and Y. Luo, "The effect of high loading rate on the behaviour and mechanical properties of coal-rock combined body," Shock and Vibration, vol. 2018, Article ID 4374530, 9 pages, 2018.

[21] M. Imani, H. R. Nejati, and K. Goshtasbi, "Dynamic response and failure mechanism of Brazilian disk specimens at high 
strain rate," Soil Dynamics and Earthquake Engineering, vol. 100, pp. 261-269, 2017.

[22] Y. Yu and T. X. Wang, "Study on relationship between splitting behaviour and elastic modulus of three georges granite," Chinese Journal of Rock Mechanics and Engineering, vol. 23, no. 19, pp. 3258-3261, 2004.

[23] Z. Luo, Z. Zhu, H. Ruan, and C. Shi, "Extraction of microcracks in rock images based on heuristic graph searching and application," Computers \& Geosciences, vol. 85, pp. 22-35, 2015.

[24] D. Li, C. C. Li, and X. Li, "Influence of sample height-to-width ratios on failure mode for rectangular prism samples of hard rock loaded in uniaxial compression," Rock Mechanics and Rock Engineering, vol. 44, no. 3, pp. 253-267, 2010.

[25] H. Lee and B. C. Haimson, "True triaxial strength, deformability, and brittle failure of granodiorite from the San Andreas Fault Observatory at Depth," International Journal of Rock Mechanics and Mining Sciences, vol. 48, no. 7, pp. 1199-1207, 2011.

[26] M. Hokka, J. Black, D. Tkalich et al., "Effects of strain rate and confining pressure on the compressive behavior of Kuru granite," International Journal of Impact Engineering, vol. 91, pp. 183-193, 2016. 


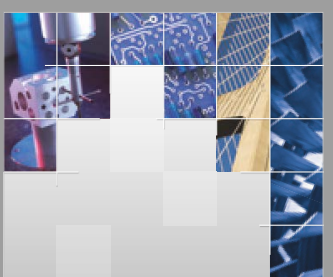

\section{Enfincering}
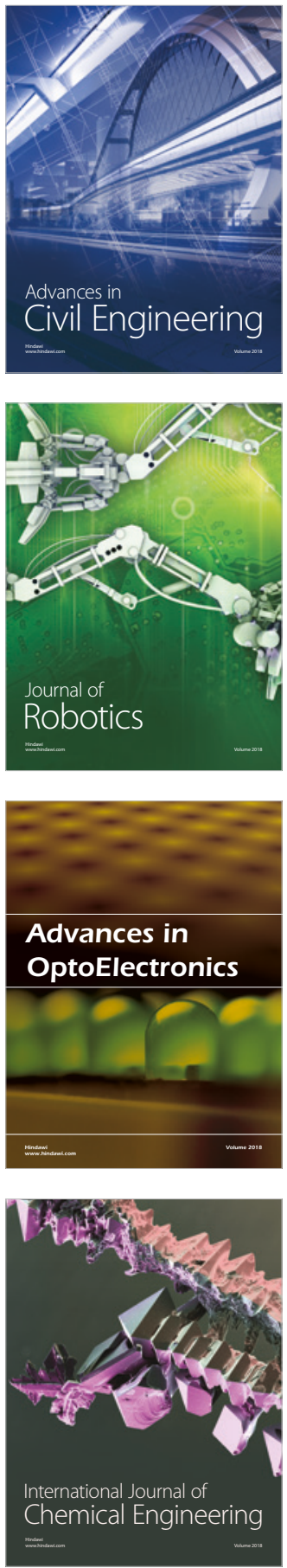

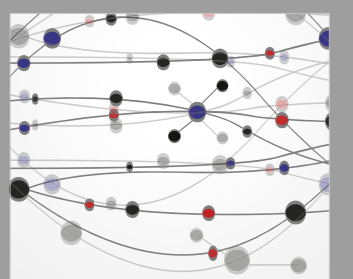

\section{Rotating \\ Machinery}

The Scientific World Journal

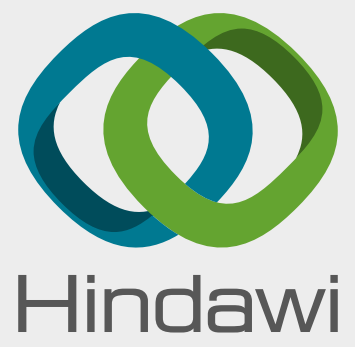

Submit your manuscripts at

www.hindawi.com
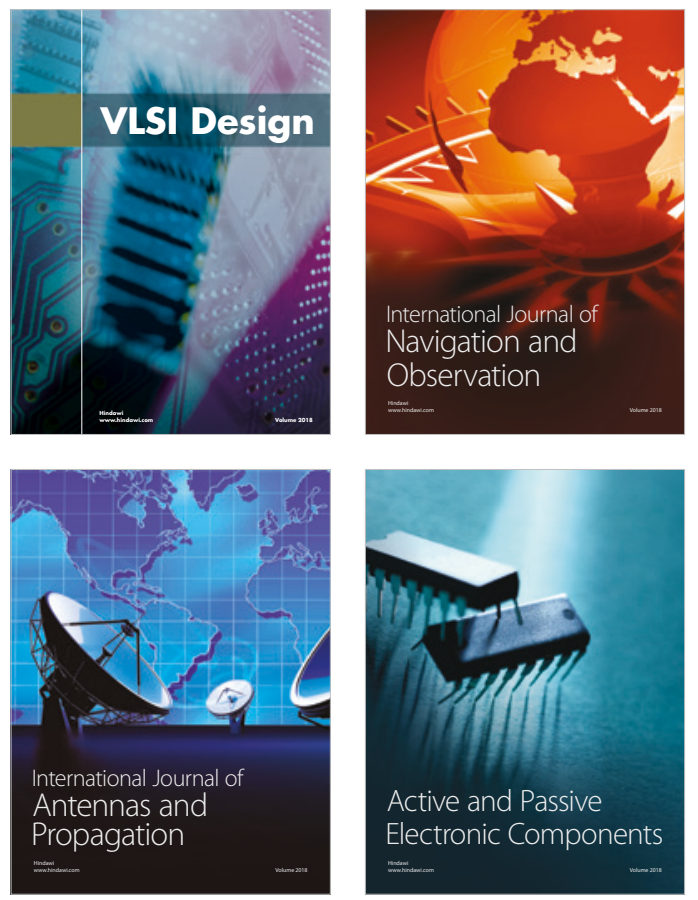
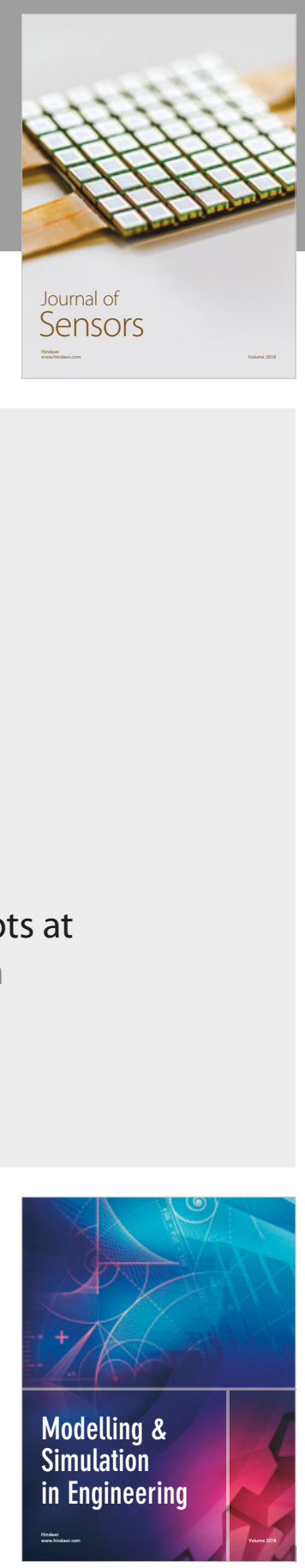

\section{Advances \\ Multimedia}
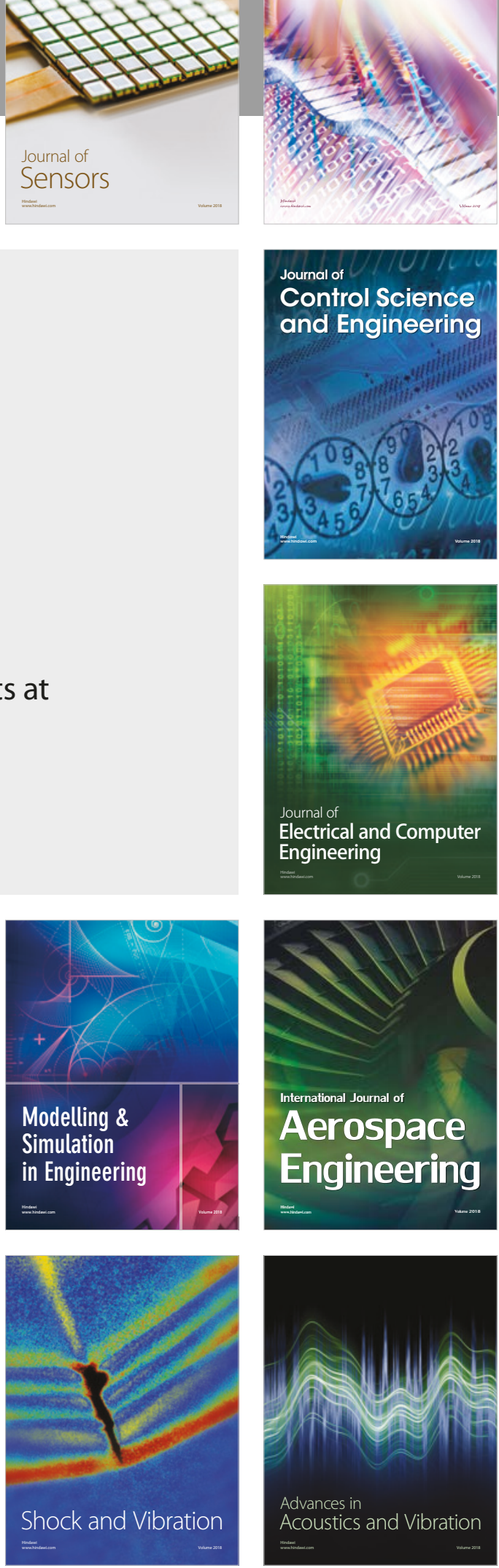